\title{
P 005 UNDERSTANDING THE BARRIERS TO IDENTIFYING CARERS OF PEOPLE WITH SUPPORTIVE AND PALLIATIVE CARE NEEDS IN PRIMARY CARE
}

Emma Carduff, ${ }^{1}$ Anne Finucance, ${ }^{1,4}$ Marilyn Kendall, ${ }^{1}$ Alison Jarvis, ${ }^{2}$

Nadine Harrison, ${ }^{1}$ Jane Greenacre, ${ }^{3}$ Scott Murray' . 'University of Edinburgh, Edinburgh, UK; ${ }^{2}$ NHS Lothian; ${ }^{3}$ Voices of Carers Across Lothian; ${ }^{4}$ Marie Curie Cancer Care

\subsection{6/bmjspcare-2014-000654.45}

Background Caring for someone at the end of life can be physically and emotionally demanding. At the same time carers are coming to terms with the imminent loss of the patient. Carers are often ambivalent about their own needs and are reluctant to self-identify as a caregiver in need of support.

Aims This study set out to explore the barriers to, and strategies for, identifying carers of people at the end of life in primary care, and to understand why carers do not self-identify.

Methods This study triangulates three sources of data - a review of the care giving literature, a synthesis of data from previous carer research, and focus groups with current and bereaved carers and health professionals.

Results Barriers were identified in three core categories. 1) Transition into the caring role was seen as a gradual process and carers did not necessarily identify with being a 'carer', meaning support was often initiated in response to a crisis with the patient or the carer. 2) As the patient's illness deteriorated, caring was all-encompassing meaning that carers were managing competing demands and prioritised the needs of the patient, often at the expense of their own. 3) The role of the GP in supporting carers was as ambiguous. GPs were perceived to lack knowledge about available services and their reactive, rather than proactive approach, meant carers were less likely to see their needs as legitimate and ask for help.

Conclusions Encouragingly, health professionals in this study acknowledged the importance of identifying and supporting carers. Strategies to identify and support carers should be commenced early in the illness trajectory to prevent crises and need to be sensitive to the complexities of the primary care context. Primary care teams also need to work together to ensure that carers' needs are legitimised so that they are empowered to self-identify. 